ly lyrical in its language, will also greatly interest animal liberationists. It would be well played as a companion piece to Henry Salt's A Lover of Animals. Non-fiction works include Stephen Vincent Benet on Writing.

The pages of Between the Species ruffle (pardon the animal-morphism) with pleasure to be able to set Negavit to print.

As for what may be expected in No. 4 (Fall, 1985), readers may look forward in particular to Dr. Michael Fox's "The BioPolitics of Sociobiology and Philosophy."

Scheduled for future issues are autobiographical essays by Tom Regan, Ingrid Newkirk, and Peter Singer, among others.

\section{IF FISH COULD SCREAM}

I had a dream

That fish could scream. So there were no fishermen

For none could bear to hear

The screams of netted fish

Or tolerate the painful cries

of those impaled on fishing lines.

Did God give silence to the fish

That we might never perceive and feel

Their fear and pain,

Just so we can eat them

With no twinge of shame

or fellow-feeling?

We niight ask what kind of God would do this To make all fish mute

And in their silence,

Suffer suffocation in our trawler nets,

Pain and terror on our hooks?

Perhaps that we might learn

To feel through silence

From the mute, the weak, the dumb,

of our kind and fish kind

And all kind great and small.

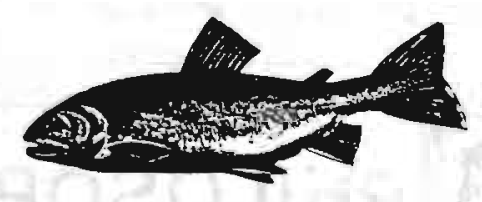

MICHAEL FOX

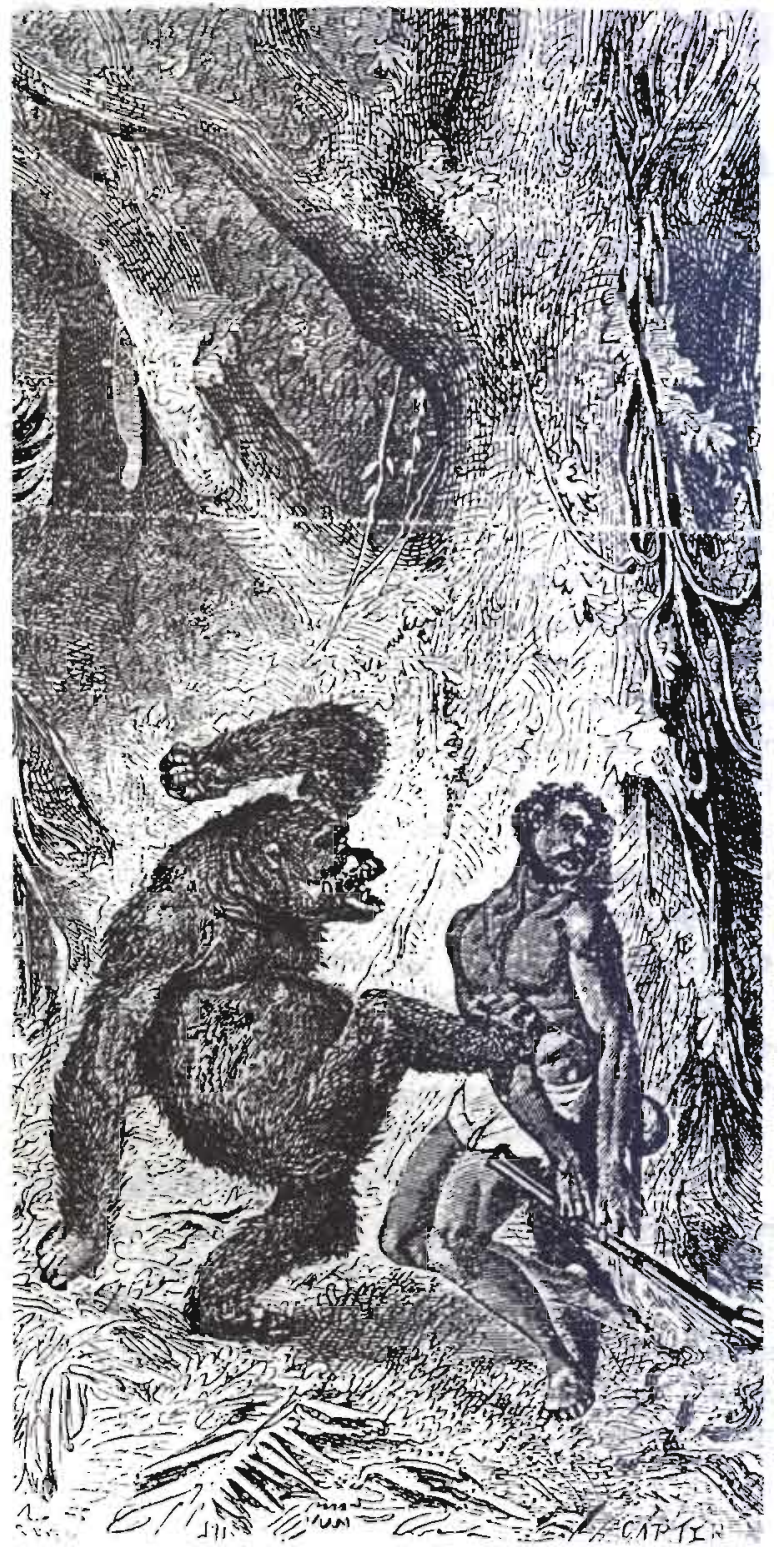

\section{EDITORS' NOTE}

Many animal rghts proponents have drawn an analogy between animal liberation and the civil rights and women's liberation movements. We agree that there is an analogy here--perhaps even more than that--and believe that this imposes a bit of a linguistic obligation on those who write about animal rights: they should not employ sexist language. Consequently, would those contributing manuscripts to Between the Species please avoid such terms as "man," "he," "fellowship," "fraternal," etc., unless a male reference is intended. 